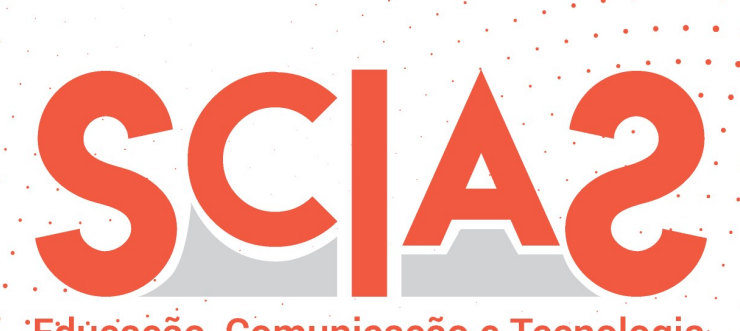

Eduçaçẳo, Comunicação e Tecnologia

Atribuição BB CY 4.0

\title{
Educação e Tecnologia na formação docente: Representações sobre jogos digitais
}

Darsoni Oliveira Caligiorne ${ }^{1}$

\section{Resumo}

$\mathrm{O}$ artigo apresenta resultados de pesquisa que objetivou identificar e analisar as representações sobre jogos eletrônicos, jogos digitais e refletir sobre estes saberes, construídos no processo de formação docente. Participaram do estudo graduandos do oitavo período do curso de Pedagogia da Faculdade de Educação da Universidade do Estado de Minas Gerais. Os dados foram coletados mediante questionário aberto, numa tentativa de evidenciar o pensamento no contexto da formação docente. Os resultados apresentam um panorama sobre as representações dos graduandos sobre as tecnologias digitais construídas no processo de formação, sendo este um fator que interfere e redefine a ação docente no processo ensino-aprendizagem.

\section{Palavras-chave}

Jogos digitais. Cultura digital. Formação docente.

Recebido em: 27/02/2019

Aprovado em: 11/09/2019

\footnotetext{
${ }^{1}$ Pedagoga, pela Pontifícia Universidade Católica de Minas Gerais, Pós-graduada em Psicopedagogia e Informática Educativa pelo Instituto de Educação Continuada da Pontifícia Universidade Católica do Estado de Minas Gerais, Mestre em Engenharia e Gestão do Conhecimento pela Universidade Federal de Santa Catarina. É professora universitária há mais de 20 anos, lecionando as disciplinas nas áreas da Didática, Letramento Digital, Práticas de Ensino, Estágio Supervisionado, Teorias Pedagógicas e Educação e Tecnologia. É integrante do Núcleo de Estudos e Pesquisas sobre Educação, Comunicação e Tecnologia (NECT-UEMG), no qual discute sobre as práticas pedagógica e tecnológicas na formação docente. Pesquisadora do Núcleo de Estudos e Pesquisa em Educação, Conhecimento e Tecnologia (NEPCED/UFMG), investiga a Cultura digital, letramento e alfabetização nas escolas públicas. É integrante do Núcleo de Pesquisa sobre Condição e Formação docente (PRODOC/UFMG) pesquisando propostas e programas de formação docente, cultura digital e currículo. e-mail: darsoni@terra.com.br
} 


\title{
Education and Technology in teaching training: Representations on digital games
}

\begin{abstract}
The article presents research results that aimed to identify and analyze representations about electronic games, digital games and reflect on these knowledge, built in the process of teacher training. The eighth period of the Pedagogy course of the Faculty of Education of the State University of Minas Gerais participated in the study. The data were collected through an open questionnaire, in an attempt to evidence the thought in the context of teacher training. The results present a panorama about the representations of the graduates on the digital technologies built in the training process, being this a factor that interferes and redefines the teaching action in the teaching-learning process.
\end{abstract}

\section{Keywords}

Digital games. Digital culture. Teacher training. 


\section{Introdução}

O processo educativo está passando por grandes transformações provocadas pela democratização da tecnologia, novos tempos, etnias, grupos sociais, tornando-se necessário buscar novos paradigmas educacionais que orientem a aprendizagem e o ensino, tanto em termos metodológicos como terminológicos. Mill, (2010) considera que em função dos tempos e espaços, em função das mudanças no mercado de trabalho e das transformações decorrentes do desenvolvimento técnico-científico, tanto o professor quanto o estudante adquirem novas configurações. O professor deixa de ser o detentor de um saber e o estudante deixa de ser um ser passivo no processo ensino-aprendizagem.

Nesta perspectiva, em que a sociedade tem profundas transformações, principalmente no que se refere à interação entre o ser humano e sua relação com o conhecimento, faz-se necessário reorganizar, apreender o mundo e transformar as novas formas de ensinar e aprender. (SILVA, 2001).

Diante de tal assertiva, o papel do professor em relação ao conhecimento, saberes e práticas devem passar por uma profunda revisão de valores, metodologias e atitudes que sejam coerentes com uma nova logica na construção do conhecimento.

Com a incorporação das novas tecnologias da informação e da comunicação no campo do ensino, novos desafios foram colocados para a prática docente e para os processos de ensino-aprendizagem. Principalmente com a universalização do uso dos computadores nas instituições educacionais, assiste-se de modo à inclusão digital. (ROSA; REZENDE; CRUZ E MELLO, 2008).

Compreendendo que a inclusão digital possibilitou ativamente o uso das ferramentas de informática no sistema educacional de diversas maneiras desde os anos de 1960, cabe ressaltar que somente por volta da década de 1980, o Brasil passou de fato a usufruir dessas tecnologias informacionais nas escolas. 
Destaca-se que a utilização no país, ocorre primeiramente nas universidades, a implementação das mídias educacionais, onde essas entidades passam a utilizar o computador como ferramentas didáticas pedagógicas no ensino científico (BRASIL, 1997).

Tal medida impulsionou o uso do computador e da Internet na escola passando a ser uma necessidade, e às vezes uma exigência, no novo ambiente comunicacional-cultural escolar "que surge com a interconexão mundial de computadores em forte expansão no início do século XXI. Novo espaço de sociabilidade, de organização, de informação, de conhecimento e de educação". (SILVA, 2004, p.02)

Sendo assim, observa-se que as instituições precisam refletir o uso dessas mídias no trabalho educacional desenvolvido com professores sobre o contexto atual de inclusão escolar digital a respeito do uso das TICs e investimentos na formação de competências que possam auxiliar de forma eficaz a metodologia do professor no processo de ensino aprendizagem e na produção e construção do conhecimento, de forma que o docente possa acompanhar positivamente as contínuas e aceleradas transformações que o sistema educacional vem sofrendo.

Por esta ótica, um dos grandes desafios são os jogos eletrônicos e digitas e a sua inclusão no processo educativo, no qual se destaca o papel do professor que muitas vezes se depara com uma ferramenta desconhecida e encontra dificuldade quando o assunto se trata do uso de recursos tecnológicos no processo educacional.

Segundo Behrens (2000) é preciso desenvolver uma abordagem pedagógica que valorize a aprendizagem colaborativa, redimensionando a metodologia desenvolvida na sala de aula, através de uma prática pedagógica fundamentada no ensino com pesquisa, através de projetos de aprendizagem que possibilitam a reflexão sobre o conhecimento acessado, num processo coletivo para a construção do conhecimento significativo. 
Partindo do pressuposto de que a sala de aula é o espaço privilegiado de negociações e de produção de novos sentidos e significados dos diferentes conceitos escolares, torna-se um desafio compreender os conhecimentos e informações produzidas sobre o uso dos suportes tecnológicos. (ALVES, 2006; GARCIA, 2012).

\section{Procedimentos}

Neste contexto, algumas questões relativas à prática e a formação do professor para a utilização de jogos digitais, surgem: Quais os conceitos de jogos, jogos eletrônicos e digitais sob a ótica dos graduandos? As respostas a essas perguntas são importantes, pois tem por objetivo refletir sobre os saberes construídos no processo de formação docente. Segundo Tardif (2014) representa um saber "que se compõe, na verdade, de vários provenientes, de diferentes fontes" (TARDIF, 2014, p.33) tanto curriculares, como profissionais. Também os saberes sociais que possui e transmite e que muitas vezes é desvalorizado.

A estratégia metodológica buscou articular conhecimento e tecnologia, envolvendo trinta e um graduandos do sétimo período do Curso de Pedagogia no contexto da Faculdade de Educação da Universidade do Estado de Minas Gerais (FaE/UEMG). A pesquisa envolveu a coleta de dados, através de um questionário aberto envolvendo a informações e reflexões acerca do fenômeno jogos digitais no processo ensino-aprendizagem e os dados coletados.

A investigação foi organizada, em um semestre $\left(1^{\circ}\right.$ de 2014), na disciplina Estudos Sobre Educação e Tecnologia: Mídia e Educação, na FaE/UEMG. Ao todo participaram da pesquisa 31 (trinta e um) graduandos (as) do VII período do curso de Pedagogia.

Os aspectos teóricos discutidos na disciplina corresponderam aos temas mídiaeducação e tecnologia na Escola. Que contribuíram para as reflexões e provocações sobre as seguintes temáticas: Jogos digitais e eletrônicos e possibilidades pedagógicas. 
A abordagem desta pesquisa é qualitativa. Segundo Minayo (2009), trabalha com dados em busca de inspirações, crenças, significados, valores e atitudes, correspondendo a um espaço mais profundo das relações com a realidade.

O instrumento de coleta de dados foi um questionário aberto aplicado na forma física, isto na forma impressa. Neste aspecto Lakatos e Marconi (2003), definem questionário como:

Questionário é um instrumento de coleta de dados, constituído por uma série ordenada de perguntas, que devem ser respondidas por escrito e sem a presença do entrevistador. Em geral, o pesquisador envia o questionário ao informante, pelo correio ou por um portador; depois de preenchido, o pesquisador devolve-o do mesmo modo. (LAKATOS e MARCONI, 2003, p.201).

A fonte de dados foi um questionário, composto por três questões abertas, para identificar os saber docente acerca dos jogos, jogos eletrônicos e jogos digitais.

\section{Dados e análises}

Diante das inovações tecnológicas, assim como a interação dos indivíduos com os recursos tecnológicos e sua manipulação, os jogos aparecem como um elemento cultural "envolve rituais, relações sociais e criação de grupos." (ARRUDA, 2014, p.04). Diante de tal premissa, torna-se importante perguntar aos graduandos "o que são jogos".

Constatou-se que a visão que os graduandos têm sobre jogos, apresentam palavras e/ou termos que segundo os dados obtidos pelos questionários, demostram os seguintes resultados conforme a Tabela 1.

Tabela 1: Questionários realizados com os graduandos sobre jogos

Ao ser feita a pergunta: 55\% dos graduandos consideram o jogo, gracejo, brincadeira, divertimento, atividade física ou intelectual que integra um sistema de regras e define um indivíduo como vencedor e outro perdedor.

Ao ser feita a pergunta: 13 \% definem o jogo como qualquer atividade em que exista a figura do jogador, regras.

Ao ser feita a pergunta: $16 \%$ dos graduandos classificaram o jogo com uma possibilidade limitada, tradição, atividade lúdica, e que passa de geração em geração. Ao ser feita a pergunta: $16 \%$ não responderam

Fonte: Dados da pesquisa (2014). 
As respostas obtidas demostra conceitos que enfatizam o jogo como elementos da cultura dos homens, desenvolvimento físico, cognitivo, social e ludicidade.

Segundo Johan Huizinga (1993) que introduz a ideia de jogo, este é entendido como uma categoria essencialmente primária a vida. Essa noção é ilustrada através da brincadeira realizada pelos caninos, no qual os animais convidam-se, a participar de uma atividade lúdica onde disputam entre si, respeitando regras. (LUCCHESE; RIBEIRO, 2014). Huizinga (1993) define jogo como "uma atividade ou ocupação voluntária, exercida dentro de certos e determinados limites de tempo e espaço, segundo regras livremente consentidas, [...] acompanhado de um sentimento de tensão, alegria e de uma consciência de ser diferente da vida cotidiana”. (HUIZINGA, 1993, p. 33)

É preciso destacar também diante das respostas, que um jogo é formal, “é nãolinear, uma vez que a ordem dos acontecimentos depende de tomadas de decisão do jogador.” ( PFUTZENREUTER; STANO, 2010, p.o2 ).

Ou seja, a identificação, decodificação, comparação, análise, síntese, representação mental, raciocínio divergente, raciocínio hipotético, curiosidade e engajamento representam o que se espera que o aluno desenvolva em um processo educacional, pois através delas é possível a construção do conhecimento. (PFUTZENREUTER; STANO, 2010, p.04)

A prática de jogos permite o desenvolvimento de capacidades necessárias à aprendizagem, bem como a manutenção e ampliação do convívio social, permite conhecer e aprender a respeitar suas diferenças culturais e étnicas.

[...] resultam dessa virtude fundamental, porque aprender como pensar, em última análise, tem a ver com aprender a tomar a decisão certa: pesar a evidência, analisar situações, consultar suas metas em longo prazo e, então, decidir. (JOHNSON, 2005, p. 34)

Outro item que abordado foi à questão referente aos jogos eletrônicos. Os dados obtidos pelos questionários, demostram os seguintes resultados conforme a Tabela 2. 
Tabela 2: Questionários realizados com os graduandos sobre jogos eletrônicos

Ao ser feita a pergunta: 42\% dos graduandos consideram os jogos eletrônicos são brincadeiras virtuais; jogos que interagem através de imagens enviadas a um dispositivo; videogame.

Ao ser feita a pergunta: $23 \%$ dos graduandos enfatizam ser um tipo particular de programa de computador; jogos de computador.

Ao ser feita a pergunta: 19\% graduandos consideram como atividade lúdica formada por ações e decisões que resultam numa condição final

Ao ser feita a pergunta: $6 \%$ dos graduandos conceituaram como sendo fruto do desenvolvimento tecnológico

Ao ser feita a pergunta: E apenas 10\% não responderam.

Fonte: Dados da pesquisa (2014).

De acordo como as respostas é possível perceber que os jogos eletrônicos refletem o formato de entretenimento, brincadeira e ludicidade, pois estes foram difundidos no inicio dos anos de 1970, com jogos de caça níquel, que era operado por moedas e descrito com jogos eletromecânicos (SILVA, 2017; LUCCHESE; RIBEIRO, 2014).

Analisando ainda as respostas dos graduandos, os jogos eletrônicos são percebidos como reflexos das grandes transformações tecnológicas, que se estendem aos recursos e dispositivos. Hoje a utilização do suporte tecnológico ultrapassa a um modelo presente em atividades lúdicas historicamente construídas como os jogos de tabuleiro, esportes, jogos de cartas entre outros, no qual as representações de formato físico, se mantem nos elementos e regras, e ocupam o espaço interativo em um formato digital. (MARTINO, 2015; SILVA, 2017)

Da década de 1970 para a atualidade, o crescimento do mercado dos jogos eletrônicos, aliado ao desenvolvimento tecnológico de dispositivos computadorizados, consolidou um mercado mundial com movimentação financeira superior a outras formas de entretenimento comercializadas em larga escala, que continua a ampliar o perfil de seus/suas consumidores/as pela sua difusão em suportes móveis e pela incorporação de seu uso em atividades educacionais e de capacitação em diferentes áreas.

https://www.snh2017.anpuh.org/site/anais).

O que caracteriza um jogo eletrônico é a sua condição de atividade lúdica, formada por regras e desafios, com uma interface que permite ao jogador criar estratégias e a desenvolver um pensamento dentro de um tempo programado para resolver cada situação proposta nas fases do jogo, que são regidas por um 
programa de computador (SCHUYTEMA apud CARVALHO et al.,2017; MENDES, 2006).

Quando indagados sobre o conceito de jogos digitais, constataram-se os seguintes resultados demonstrados conforme a Tabela 3.

Tabela 3: Questionários realizados com os graduandos sobre jogos digitais Ao ser feita a pergunta: $38 \%$ dos graduandos consideram este ser um videogame; jogos eletrônicos; brincadeiras regidas por um programa de computador.

Ao ser feita a pergunta: $23 \%$ dos graduandos entendem que o jogo permite a interação entre humano e computador e possibilita o entretenimento; apresenta regras e desafios.

Ao ser feita a pergunta: $13 \%$ dos graduandos os jogos digitais são games destinados a crianças e adolescentes com o intuito de educar os jogadores e envolve conhecimentos Ao ser feita a pergunta: 26\% dos graduandos não responderam

Fonte: Dados da pesquisa (2014).

Analisando as respostas apresentadas verifica-se que são marcados pela sociedade pós-moderna, pela presença das tecnologias, criando um ambiente "povoado pela cibernética, a robótica industrial, a biologia molecular, a medicina nuclear, a tecnologia de alimentos (...)” (SANTOS, 2010, p.26) que possibilitam aos jogos uma nova configuração em sua forma e ações e decisões até então impossíveis.

A tecnologia high tech invade as lojas, as telas da TV e dos computadores, anunciando brinquedos mais sedutores que permitem aos seus consumidores irem além do faz-de-conta que estava presente na infância da geração de hoje está na adultez, a exemplo dos jogos eletrônicos. (ALVES, 2006, p.147).

Os jogos eletrônicos, ou videogames, diferem dos jogos digitais à medida que este incorporar outras mídias por consequência do avanço da tecnologia digital, apresentando dimensões e narrativas mais complexas. Os jogos eletrônicos passam a apresentam configurações e características próprias do mundo virtual, construída no ciberespaço, e fazem parte da cultura dos chamados nativos digitais. Que nasceram imersos no mundo digital (PRENSKI, 2012) com desafios, narrativas, gráficos que compõe o mundo virtual interativo, e requer dos jogadores habilidades complexas e diferenciadas (ALVES, 2006).

Portanto, a atividade com jogos eletrônicos, expressa uma construção cultural, social e econômica vinculada ao desenvolvimento da informática, no qual os 
jogos de videogames (ou vídeo games) têm destaque e presença na vida de crianças, jovens e adultos. (SAVI; ULBRICHT, 2008). Os video-games e computadores são, antes de tudo, um ambiente ou um meio físico através do quais jogadores interagem e ao serem produzidos através de linguagem computacional passam a ser conceituados por jogos digitais. (LUCCHESE; RIBEIRO, 2014).

De fato o nome utilizado por nós para designar o equipamento é o nome dado ao tipo de jogo, o equipamento é classificado como console, porém chamado no Brasil também por vídeo-game. Os videogames seriam realmente os jogos utilizados nos consoles, ou traduzindo, seriam os jogos de vídeo. A forte influência cultural exercida no campo dos jogos digitais pela língua inglesa nos leva a tentar minimizar as expressões estrangeiras, utilizando-as apenas quando for estritamente necessário. (PINHEIRO, 2007. p.25).

Um dos aspectos abordados no questionário refere-se às características marcantes não apenas dos jogos digitais, mas de todos os jogos, que esta relacionada à sua condição de produto da indústria do entretenimento, no entanto o jogo vai além da distração.

O jogo é mais do que um fenômeno fisiológico ou um reflexo psicológico. Ultrapassa os limites da atividade puramente física ou biológica. É uma função significante, isto é, encerra um determinado sentido. No jogo existe alguma coisa "em jogo" que transcende as necessidades imediatas da vida e confere um sendo a ação. Todo o jogo significa alguma coisa. (HUIZINGA, 1993, p.04)

Outra característica dos jogos digitais se refere às regras e desafios, que definem o que é possível e permitido. Tais regras são interpretadas pelos algoritmos do computador, não havendo espaço para negociação, não permite a flexibilidade comum dos jogos não digitais, pois não existe espaço para negociação das regras. No entanto, as regras e desafios, que são "coordenadas através do programa de executável”, e o que garante a interação entre jogador e o ambiente. (LUCCHESE; RIBEIRO, 2014; ALVES, 2006).

Outro dado interessante é a presença do termo game, atividade que marca a evolução do "desenvolvimento do raciocínio na era da eletrônica" (GREENFIELD, 1988), no campo da tecnologia, e que proporcionou a otimização dos games. (ALVES, 2006) 
Os games são sinônimos de jogos eletrônicos, jogos estes com regras definidas, níveis de dificuldade, pois há um objetivo a ser alcançado que, se não for atingido levará a derrota do jogador.

Segundo Alves (2014) game é uma atividade, que envolve regras, limites de tempo e espaço. Os games são constituídos de uma capacidade de processamento de dados, que permite a geração de dados cada vez mais realísticos. Ao aplicar estes elementos como mecanismos de jogos, para ações de não jogo, realiza-se a gameficação.

Gamificação ou gameficação é o uso de mecanismos de jogos aplicados em situações que não correspondem a jogos, ou seja, para solucionar problemas práticos ou ainda despertar engajamento entre um publico específico pode-se utilizar elementos dos games. (TONEIS, 2016).

Tal ação envolvendo os sujeitos em desafios mediados por regras, proporcionando a interatividade, imersão e interconectividade, que constitui em um ambiente de desafio e investigação, e possibilita a construção de estratégias cognitivas no qual, através de escolhas aprende-se a ter um repertório de soluções. (LEMOS; PEDRO, 2012)

[...] entende que os jogos são tecnologias intelectuais, promovendo a construção ou reorganização de funções cognitivas e contribui para determinar o modo de percepção e intelecção pelo qual o sujeito conhece o objeto. (LÉVY apud ALVES, 2006, p. 146).

\section{Considerações finais}

Com esta pesquisa, foi possível constatar que operar com tecnologias digitais, através de "jogos que internalizam os procedimentos necessários para utilizálos” (RIBEIRO, 2014, p.317) no campo educacional, estão associada a questões como: preparação para o mundo do trabalho; integração de habilidades técnicas fundadas nos processos sociais e cognitivos; saberes, habilidades e atitudes tecnológicas; de inclusão e exclusão digital.

Segundo Giroux (1996) ao refletir sobre as questões que envolvem a formação docente e o uso das TICs como recurso didático destaca que o domínio das ferramentas tecnológicas e sua utilização de forma acrítica têm deteriorado a função social do conhecimento e, por conseguinte a função social do trabalho 
docente. Por outro lado, a utilização das novas tecnologias da informação e da comunicação como ferramenta pedagógica auxilia nas formas de interação e no processo de apropriação e construção do conhecimento.

Também foi possível constatar a natureza social do saber, que é um conjunto de saberes provenientes de diversas fontes, e que a mistura destas fontes, definem o saber docente, que são fundamentais, mas que são desvalorizados em relação aos saberes que possui. (TARDIF, 2014).

Segundo Charlot (2000), o saber faz surgir um sujeito que mantém com o mundo uma relação ampla, pois não há saber senão para o sujeito. O professor, o sujeito em questão, tem um saber que deve ser considerado, e este não constitui apenas de um conhecimento científico e pedagógico.

Uma vez que todo saber implica em um processo de aprendizagem e de formação, no qual aprender é estabelecer uma relação com o saber, um saber que permite certo domínio do mundo no qual vive. As respostas do questionário permitem comunicar com outros e partilhar o mundo com eles, viver certas experiências e assim tornar-se, mais seguro de si, mais independente e desta forma o saber envolverá o sujeito.

É imprescindível que o professor neste processo de respostas, se reconheça como ser pensante, ator do processo, que assume a sua pratica a partir dos significados que ele mesmo dá aos conceitos apresentados. Um sujeito que possui conhecimentos e um saber-fazer a partir do qual ele a estrutura e orienta. (TARDIF, 2014).

Um dos fatores que interferem na construção da identidade docente está relacionado à presença das tecnologias da informação e comunicação (TICs) na sala de aula, que redefinem as praticas e o trabalho docente, portanto os processos de formação docente. Apesar do grande potencial pedagógico, incorporar as TICs, no cotidiano da sala de aula, envolve a materialidade e subjetividade, isto é, os professores e sua relação com a tecnologia. 
Segundo Pacheco \& Flores,

"os professores são atores indispensáveis no processo curricular e porque deles depende, em grande medida, qualquer propósito de inovação educativa, a sua formação constitui uma vertente que não se pode escamotear." (Pacheco \& Flores apud LEMOS; PEDRO, 2012, p.3147).

Com essa perspectiva, e uma vez que, na atividade pedagógica, o professor é um elemento primordial na concretização do currículo (SACRITÀN, 200o) que permite a constituição de sua identidade e contribui para ampliar a função do trabalho docente (NOGUEIRA, 2006).

Segundo Gatti e Barreto (2009), a reflexão crítica sobre o seu trabalho na medida em que eles participaram na construção de ações pedagógicas e digitais. É um momento de senso prático, “que é a lógica da prática, que a não ser por meio de construções que destroem como tal, enquanto não se questionar o que são” (BOURDIEU, 2009, p.25).

Tudo leva a crer que os saberes adquiridos durante a trajetória pré-profissional, isto é, quando da socialização escolar tem um peso importante na compreensão da natureza dos saberes, do saber-fazer e do saber-ser que serão mobilizados e utilizados em seguida quando da socialização profissional e no exercício do magistério. (TARDIF, 2014, p 69).

A incorporação e reconhecimento da era digital, no caso os jogos eletrônicos e digitais, como uma forma de conhecimento, no processo de aprendizagem torna-se um desafio para a ação docente, pois há uma mudança dos saberes, para os procedimentos de transmissão dos saberes. Isto é, uma transformação entre saber e formar entre aprender e ensinar de forma criativa, dinâmica, significativa e transformadora. (MASSETO, 2000; TARDIF, 2014).

Um dos fatores que interferem na construção da identidade docente está relacionado à presença das tecnologias da informação e comunicação (TICs) na sala de aula, que redefinem as praticas e o trabalho docente, portanto os processos de formação docente.

Apesar do grande potencial pedagógico, incorporar as TICs, no cotidiano da sala de aula, envolve a materialidade e subjetividade, isto é, os professores e sua relação com a tecnologia. É preciso que os processos de formação desenvolvam 
competências e atitudes para transformar as ferramentas tecnológicas em ferramentas pedagógicas. Portanto a aprendizagem e o uso das novas ferramentas em aula devem considerar as atitudes e expectativas dos docentes a respeito das potencialidades e virtudes das TICs.

\section{Referências}

ALVES, Flora. Gamification: como criar experiências de aprendizagem engajadoras: um guia completo do conceito a prática. São Paulo: DUS Editora. 2014.

ALVES, Lynn, Jogos eletrônicos e screenagers; possibilidades de desenvolvimento e aprendizagem. In: ALVES, Lynn; SANTOS, Edméa (Org.). Práticas pedagógicas e tecnologias digitais. Rio de Janeiro: E-papers, 2006. p.143-157.

ARRUDA, Eucídio Pimenta. Fundamentos para o desenvolvimento de jogos digitais. Porto Alegre: Bookman, 2014.

BEHRENS, Marilda Aparecida. Projetos de aprendizagem colaborativa num paradigma emergente. In: MORAN, José Manuel; MASSETO, Marcos Tarcisio; BEHRENS, Marilda. Aparecida. Novas tecnologias e mediação pedagógica. São Paulo: Papirus, 2000. p. 67-132.

BOURDIEU, Pierre. O senso prático. Trad. Maria Ferreira. Petrópolis, RJ: Vozes, 2009, p.07-40.

BRASIL, Ministério da Educação - Secretaria de Educação a DistânciaPROINFO - Programa Nacional de Informática na Educação. Aprender a construindo: A Informática de transformando com professores. Brasília- DF, 1997.

CARVALHO, Sandro de Paiva; PEDROSA, Stella Maria Peixoto de Azevedo; ROSADO, Luiz Alexandre da Silva. A produção de jogos eletrônicos para a educação: investigando os bastidores. Revista Educação Unisinos, São Leopoldo, n.3, p.374-386, set/dez. 2017. Disponível em: $<$ http://www.revistas.unisinos.br/index.php/educacao/article/view/edu.2017.2 13.11 > Acesso em:12 outubro 2017.

CHARLOT, Bernard. Da relação com o saber: elementos para uma teoria. Trad. Bruno Magne. Porto Alegre: Artes Médicas Sul, 2000.

GARCIA, Regina Leite; ALVES, Nilda. Sobre formação de professores e professoras: questões curriculares. In: LIBANEO, José Carlos; ALVES, Nilda (Org.).Temas de pedagogia: diálogos entre didática e currículo. São Paulo: Cortez, 2012, p.498-510. 
GATTI, Bernadete Angelina; BARRETO. Elba Siqueira de Sá (Orgs.). Professores do Brasil: impasses e desafios. Brasília: UNESCO, 2009.

GIROUX, Henri. Jovens, diferença e educação pós-moderna. In: CASTELLS, Manuel (Org.). Novas perspectivas críticas em educação. Porto Alegre: Artes Médicas, 1996. p.63-85.

GREENFIELD, Patrícia. O desenvolvimento do raciocínio na era eletrônica: os efeitos da tv, computadores e videogames. Trad. Cecília Bonamiel, São Paulo: Summus, 1988.

HUIZINGA, J. Homo Ludens: o jogo como elemento da cultura. 4. ed. Tradução João Paulo Monteiro. São Paulo: Perspectiva, 1993.

JOHNSON, Steve. Surpreendente! A televisão e o videogame nos tornam mais inteligentes. Rio de Janeiro: Campus, 2005.

LAKATOS, Eva Maria \& MARCONI, Marina de Andrade. Fundamentos de metodologia científica -1. 05. Ed. São Paulo: Atlas, 2003.

LEMOS, Susana; PEDRO, Neuza. Competências digitais dos docentes do ensino superior. In. Congresso Internacional TIC e Educação, 2., Lisboa. Anais eletrônicos... Lisboa: Instituto de Educação da Universidade de Lisboa, 2012. Disponível em:< http://ticeduca.ie.ul.pt/atas/pdf/atas.pdf > Acesso em: 25 novembro2013.

LUCCHESE, Fabiano; RIBEIRO, Bruno. Conceituação de Jogos Digitais. Universidade Estadual de Campinas. Campinas, 2005.Disponível em:<http://www.dca.fee.unicamp.br/ martino/disciplinas/ia369/trabalhos/t1 g.3.pdf > Acesso em: 04 maio 2014.

MARTINO, Luís Mauro Sá. Teoria das mídias digitais: linguagem, ambientes, redes. 2.ed. Petrópolis, RJ: Vozes, 2015.

MASETTO, Marcos Tarcisio. Mediação pedagógica e o uso da tecnologia. In: MORAN, José Manuel; MASETTO, Marcos Tarcísio; BEHRENS, Marilda Aparecida. Novas tecnologias e mediação pedagógica. São Paulo: Papirus, 2000. p.133- 173 .

MENDES, Claudio Lúcio. Jogos eletrônicos: diversão, poder e subjetivação. Campinas, São Paulo: Papirus, 2006.

MILL, Daniel. Reflexões sobre a formação de professores pela/para educação a distância na contemporaneidade: convergência e tensões. Anais: $X V-$ Encontro Nacional de Didática e Práticas de Ensino, Belo Horizonte: Autentica. 2010.

MINAYO, Maria Cecília de Souza (Org.). Pesquisa Social: teoria, método e criatividade. 28. Ed. Petrópolis, Rio de Janeiro: Vozes, 2009, p.21-23.

NOGUEIRA, Solange Maria do Nascimento. Integração formação docente inicial e continuada com a mediação de didática \& novas tecnologias. In: 
SANTOS, Edméia; ALVES, Lynn (Orgs.). Práticas pedagógicas e tecnologias digitais. Rio de Janeiro: E-papers, 2006. p.31-56.

PFUTZENREUTER, Edson do Prado; STANO, Rita de Cássia Magalhães Trindade. Jogos como elemento mediador no processo de construção de conhecimento no espaço universitário. In: Seminário Jogos, Educação e Comunicação: Construindo Novas Trilhas, 04, Salvador, BA: 2008. Disponível em:

$<$ http://www.comunidadesvirtuais.pro.br/seminario4/trab/epp rcmts.pdf $>$ Acesso em: 25 agosto 2010.

PINHEIRO, Cristiano Max Pereira. Apontamentos para uma aproximação entre jogos digitais e comunicação. 2007. 201f. Tese (Doutorado). Programa de Pós-graduação em Comunicação, Pontifícia Universidade Católica do Rio Grande do Sul. Porto Alegre, 2007.

PRENSKY, Marc. Aprendizagem baseada em jogos digitais. Trad. Eric Yamagute, São Paulo: Editora Senac, 2012.

RIBEIRO, Ana Elisa. Tecnologia digital. In: Glossário Ceale. Belo Horizonte:UFMG/ Faculdade de Educação.2014. p.317- 318.

ROSA, Wagner; REZENDE, Lucinea Aparecida de; CRUZ E MELO, Carlo Alessandro Galdino. O processo de ensino e aprendizagem a partir da prática da encenação com o uso de recursos audiovisuais. Londrina, PR: UEL/PUCPR, 2008.

SACRISTÀN, José Gimeno. O currículo uma reflexão sobre a Prática. Trad. ROSA, Ernani Ferreira da Fonseca. Porto Alegre: Artmed, 2000.

SANTOS, Milton. Por uma outra globalização: do pensamento único à consciência universal. 19 ed. Rio de Janeiro: Record, 2010.

SAVI, Rafael; ULBRICHT, Vania Ribas. Jogos digitais educacionais: benefícios e desafios. Revista Renote, Universidade Federal do Rio Grande do Sul, n.1, junho. 2008.2 Disponível em: $<$ https://seer.ufrgs.br/renote/article/view/14405>Acesso em: 12 outubro 2014.

SILVA, Alex Alvares. Aprendizagem histórica e jogos eletrônicos: a consciência histórica entre o conhecimento e a simulação. In: Simpósio Nacional de História - Contra os preconceitos: história e democracia, 29., Brasília. Anais eletrônicos... Brasília: UNB, 2017. Disponível em: < https://www.snh2017.anpuh.org/site/anais\#A > Acesso em: 27 agosto 2017.

SILVA, M. Internet na escola e inclusão. Tecnologias na escola - Ministério da Educação. 2004. Disponível em:< http://portal.mec.gov.br/seed/arquivos/pdf/2sf.pdf >. Acesso em: 19 set. 2014. 
SILVA, Marco. A sala de aula interativa: a educação presencial e a distancia em sintonia com a Era Digital e com a cidadania. Boletim Técnico Senac, Rio de Janeiro, v.27, n.02, p. 43-49. Mai./ago.2001.

TARDIF, Maurice. Saberes docentes e formação profissional.17.ed.Petrópolis, RJ:Vozes, 2014.

TONÉIS, Cristiano Natal. Os games na sala de aula: games na educação ou a gamificação da educação? Santa Monica, Florianópolis:Editora Bookes. 2016. 